\title{
Treatment of Exudative Age-related Macular Degeneration: Focus on Aflibercept
}

\author{
Alfredo García-Layana ${ }^{1,2} \cdot$ Marta S. Figueroa ${ }^{2,3} \cdot$ Javier Araiz $^{2,4}$. \\ José M. Ruiz-Moreno $^{2,5}$ - Francisco Gómez-Ulla ${ }^{2,6} \cdot$ Luis Arias-Barquet $^{2,7}$. \\ Nicholas Reiter ${ }^{1}$
}

Published online: 6 October 2015

(c) The Author(s) 2015. This article is published with open access at Springerlink.com

\begin{abstract}
A formulation of aflibercept for intravitreal injection (Eylea) is approved for the treatment of patients with exudative age-related macular degeneration (AMD). Aflibercept has a significantly higher affinity for Vascular endothelial growth factor (VEGF)-A compared with other monoclonal anti-VEGF antibodies. In addition to binding all VEGF-A isoforms, aflibercept also blocks other proangiogenic factors such as VEGF-B and placental growth factor. The VIEW 1 and 2 trials showed this drug achieves improved results in patients with exudative AMD similar to those obtained with monthly ranibizumab, using a bimonthly treatment regimen after a loading dose of three intravitreal injections, which translates to less use of
\end{abstract}

Alfredo García-Layana

aglayana@unav.es

1 Department of Ophthalmology, Clinica Universidad de Navarra, Pio XII 36, 31080 Pamplona, Navarra, Spain

2 Sociedad Española de Retina y Vítreo (SERV), Red Temática de Investigación Cooperativa Oftared, Instituto de Salud Carlos III, Madrid, Spain

3 Vissum Madrid, Department of Retina and Vitreous, Hospital Universitario Ramón y Cajal, Madrid, Spain

4 Ophthalmology Service, Hospital San Eloy, Barakaldo, Bizcaia, Spain

5 Instituto Europeo de la Retina, Clínica Baviera, Universidad de Castilla La Mancha, Albacete, Spain

6 Instituto Oftalmológico Gómez-Ulla, Santiago de Compostela, A Coruña, Spain

7 Ophthalmology Service, Hospital Universitari de Bellvitge, L'Hospitalet de Llobregat, Barcelona, Spain healthcare resources. There is a subgroup of patients that present with persistent fluid after the loading dose that could benefit from monthly injections or personalized proactive treatment after the first year. In the second year of treatment, the Treat and Extend patterns can permit even more lengthening of the time between injections. More data are needed to confirm the optimal monitoring and retreatment dosing, to maintain long-term efficacy. Other preliminary data suggest that patients that do not respond to other anti-angiogenics and patients with special pathologies such as polypoidal choroidopathy or retinal angiomatous proliferation can improve upon switching to aflibercept. To date, the safety profile of aflibercept is excellent and is comparable to other anti-angiogenic treatments.

\section{Key Points}

Aflibercept is the most recent anti-angiogenic treatment for age-related macular degeneration.

There are advantages compared with ranibizumab and bevacizumab because it binds multiple members of the vascular endothelial growth factor family and placental growth factor with higher affinity.

Injected bimonthly after a three-monthly loading dose, which translates to less use of healthcare resources.

Non-responders to other anti-angiogenics and patients with special variants of age-related macular degeneration can benefit upon switching to aflibercept. 


\section{Introduction}

Neovascular (also referred to as "exudative" or "wet") age-related macular degeneration (AMD) is characterized by choroidal neovascularization. This serious pathology has the consequence of loss of central vision, which significantly affects the patient on physical, emotional, and social levels [1-3]. Vascular endothelial growth factor (VEGF) has been identified as the principal mediator of new blood vessel growth [4-7]. Aflibercept is the most recent anti-angiogenic treatment with some advantages compared to prior options, ranibizumab and bevacizumab because it binds multiple members of the VEGF family, with high affinity for the VEGF-A and placental growth factor (P1GF) isoforms [8-10]. These isoforms play a key role in the development of the choroidal neovascularization associated with exudative AMD [11, 12]. Additionally, the prolonged intravitreal half-life of aflibercept compared with ranibizumb can translate to a lower treatment load in terms of injections, monitoring, and medical visits.

This review aims to define the current role aflibercept plays in the treatment of patients with exudative AMD in daily clinical practice. The presentation of a treatment algorithm for exudative AMD with aflibercept will aid in clinical decision making to obtain better visual results, individualize treatment, and avoid overtreatment over the disease course.

\section{Therapeutic Approach to the Patient with Exudative AMD with Ranibizumab and Bevacizumab}

AMD is the leading cause of blindness in the elderly in the Western world [13-15]. Although various risk factors have been identified, the natural evolution of AMD is still poorly understood [15]. Various clinical trials have shown that the intravitreal injection of drugs that inhibit VEGF produce significantly better visual acuity (VA) in patients with exudative AMD [16-19].

\subsection{Monthly Dosing with Ranibizumab}

Ranibizumab was approved for the treatment of exudative AMD based on results from two phase III trials: ANCHOR (patients with predominantly classic choroidal neovascularisation) and MARINA (patients with minimally classic or occult choroidal neovascularisation) $[16,17,20]$. Ranibizumab treatment resulted in improvements in VA that were maintained with monthly treatment, resulting in VA gains at month 12 of 8.5-11.3 letters in ANCHOR and 6.5-7.2 letters in MARINA. Based on the MARINA [16] and ANCHOR $[17,20]$ studies, the fixed monthly regimen was established as the principal treatment option. However, the high costs and level of care associated with a fixed treatment regimen, together with the possibility of administering unnecessary treatments to some patients, has made it desirable to search for other treatment patterns that maintain efficiency by reducing the number of injections and visits. In Europe, ranibizumab is licensed for monthly dosing until VA is stable, followed by monitoring and resumption of treatment as needed. In the USA, ranibizumab once monthly is recommended; however, patients may receive three or four monthly doses followed by less frequent dosing with regular assessments.

Currently, the most commonly used treatment regimens for exudative AMD with anti-VEGF drugs are the "pro re nata' (PRN, as needed or by discretion) pattern and an extended maintenance regimen known as 'Treat and Extend' (or inject and extend). Both patterns have an initial loading phase of three-monthly injections.

\subsection{PRN Regimen vs. Monthly Dosing with Ranibizumab or Bevacizumab}

The PRN regimen with ranibizumab was initially evaluated in the PrONTO and SUSTAIN trials [21, 22] and afterwards in other clinical trials where ranibizumab or bevacizumab were compared [18, 23, 24]. After an initial loading dose, patients were observed monthly and were treated according to criteria such as VA loss, presence of hemorrhage in the macular area, and optical coherence tomography (OCT) findings ('Treat and Observe'). Unless VA loss, hemorrhage, or an increase in fluid or macular thickness occurs, patients are not treated and are seen again at 4 weeks. In this way, the PRN regimen is an individualized reactive treatment in which patients with exudative AMD are treated when there are signs of neovascular activity. A negative aspect to consider with this regimen is that the treatment is delayed (the patient is treated when the disease worsens). The PRN pattern will reduce the number of injections; however, given that monthly follow-up is necessary to determine the need to treat or not, it does not reduce the frequency of scheduled provider care.

Because bevacizumab and ranibizumab have similar binding patterns, it was hypothesized that bevacizumab may be as effective as ranibizumab in the treatment of neovascular AMD, and may provide a less expensive alternative to approved substances specifically adapted for intraocular use. The CATT was the first of the ranibizumab vs. bevacizumab trials $[18,24]$, designed to compare not only the non-inferiority of the two drugs but also to compare a monthly regimen with a PRN protocol. At 1 year, the average improvements in VA were +8.0 letters (bevacizumab monthly), +8.5 letters (ranibizumab monthly), +5.9 letters (bevacizumab PRN), and +6.8 letters 
(ranibizumab PRN). No significant differences in VA were noted between drugs. More eyes treated with ranibizumab demonstrated resolution of fluid. Generally, switching during the second year from monthly to PRN treatment resulted in a greater mean decrease in vision, but still the mean gain in VA was similar for both drugs (bevacizumabranibizumab difference, -1.4 letters).

The IVAN trial randomized patients to receive monthly or discontinuous ranibizumab or bevacizumab [23]. Those treated with monthly bevacizumab gained -1.99 fewer ETDRS letters of VA than those receiving monthly ranibizumab. VA gain was nearly the same in patients receiving discontinuous as in those receiving monthly injections (discontinuous - continuous $=-0.35$ letters). At 2 years, the IVAN study showed that bevacizumab was neither non-inferior nor inferior to ranibizumab (mean difference -1.37 letters) and concluded that for VA, both drugs have similar efficacy. In summary, the CATT and IVAN results indicate that ranibizumab and bevacizumab both confer solid visual function benefits.

In light of this finding, clinicians may be more inclined to use the less expensive bevacizumab as therapy for exudative AMD. In USA, the proportion of patients treated with bevacizumab greatly exceeded those treated with ranibizumab. Lad and colleagues showed that the use of bevacizumab as initial treatment for neovascular AMD among Medicare users was nearly double that of ranibizumab (66.5 vs. $33.5 \%$ ) [25]. In Europe, there is a current conflict on bevacizumab between health authorities in European Union (EU) member states and the EU drug regulators. The Euretina Guidelines recommends that each treatment decision is based on an individual agreement between the treating physician and patient, and must be the consequence of a comprehensive discussion of treatment alternatives and incalculable risks. Informed consent after discussing the optimal benefit, comfort, and risks and the off-label status of the drug is mandatory [26].

\section{3 'Treat and Extend' Regimen}

The 'Treat and Extend' [27-31] pattern implies a continued treatment but at treatment and follow-up intervals greater than 1 month. Patients are treated monthly until signs of activity are not observed, according to criteria such as VA loss, biomicroscopy of the macular area, and OCT findings. Once vision is stabilized, follow-up intervals are spaced out in a sequential manner by 2 weeks provided there are no signs of exudate or recurrence. Patients receive treatment each time they are evaluated regardless of disease progression, using the signs of neovascular activity to shorten or lengthen the follow-up period. If signs of activity are detected, visit and treatment intervals are shortened to 4 weeks until signs of disease stability are seen again. This individualized therapeutic strategy can be considered proactive. Given that exudative AMD is a chronic disease, its treatment should be assumed to be long term. The philosophy of this pattern is to reduce recurrences while administering less injections and requiring less visits than fixed protocols. Additionally, the potential risk of unnecessarily treating some patients is reduced [32, 33].

\subsection{Other Treatment Regimens}

In the 'Wait and Extend' regimen [34], after an initial loading dose, a flexible treatment regimen is applied during the maintenance phase depending on disease progression. Wait and extend is also an "as-needed" protocol (PRN) where the injection is only performed in case of disease activity. Although the PRN protocol has reduced the burden of injections, the burden of follow-up visits still needs to be improved. PRN requires monthly monitoring. By contrast, in the 'Wait and Extend' regimen, in the case of no activity of the lesion, the follow-up visits were progressively spread out to a maximum of 8 weeks apart. In the event that active neovascularization is appreciated, patients are treated and re-examined every 4 weeks until reaching established criteria. Although results of this therapeutic pattern are promising with regard to the reduction in the number of injections, as well as follow-up visits, there is the risk of leaving the patient without therapeutic coverage for 3-4 months. Lengthening the followup periods without treatment could delay the detection of disease reactivation with consequential VA loss.

The 'Quarterly capped PR' [35], the 'FUSION' [36], and the 'Observe and Plan' regimens [37, 38] are other possible protocols of treatment that have not been evaluated thoroughly and not widely used.

\section{Exudative AMD Treatment Implications in Real Clinical Practice}

The impressive benefit of antiangiogenic therapy in the context of the clinical trials has been widely recognized. [16-24]. However, the results obtained in observational studies in real clinical practice indicate that although initial improvement is seen after the loading phase, the visual improvement is not maintained in the maintenance phase.

In the study performed by the Lumiere group in France, the average gain in daily clinical practice (standard deviation) was 3.2 (14.8) ETDRS letters at 12 months in patients treated with intravitreal ranibizumab [39]. Less than $40 \%$ of the patients received the recommended treatment of three initial monthly injections. Additionally, $50 \%$ of patients had to wait more than 8 days for the initial 
anti-VEGF treatment and the average number of injections of ranibizumab was 5.1 during the 12-month period.

The joint retrospective analysis of records from Germany, Holand, Belgium, and Sweden, in the framework of the LUMINOUS study, has demonstrated that the average ETDRS letter improvement at 12 months with ranibizumab treatment in routine clinical practice was $0,5.6,2.5$, and 1 with an average of 4.3, 5.5, 5.0, and 4.7 injections, respectively [40].

In the multinational AURA study, the patients received an average of five injections in the first year and 2.2 in the second year, the changes in VA being +2.4 and +0.6 in the first and second year, respectively [41]. In this study, most patients received ranibizumab throughout. A minority of patients also received treatment with bevacizumab and pegaptanib. Another multinational study (EPICOHORT) carried out in Europe after ranibizumab treatment has described VA improvements of 1.5 letters at 1 year and 1.3 letters at 2 years [42]. Similar visual results have been described in observational studies in the United Kingdom, Spain, Portugal, Italy, Denmark, Germany, and Australia [43-50].

As shown, in real clinical practice, the improvement obtained in the clinical trials is not achieved. This could be because of the use of reactive protocols that wait until the reactivation of the disease retreats, which leads to insufficient number of visits and injections during the maintenance phase. To conserve the visual improvements during the loading phase in the long-term follow-up of patients with exudative AMD using a reactive protocol, strict patient follow-up is necessary to treat the signs of reactivation, as soon as they appear. If the treatment is delayed, vision loss occurs, which in most cases will be irreversible. Another alternative is to use proactive treatments.

\section{Aflibercept: Pharmacological Characteristics}

Aflibercept (VEGF Trap-Eye) is a recombinant fusion protein obtained through biological engineering, in which extracellular domains (epitopes) of the human VEGF 1 and 2 receptors are incorporated, fused with the Fc fragment of an immunoglobulin $\mathrm{G}$ ( $\operatorname{IgG}$ ) molecule, and formulated with an osmotic solution for intravitreal administration. It was developed using the technology Traps in which parts of two receptors are used along with a constant region of $\mathrm{IgG}$ to create a soluble decoy (or trap) receptor that has higher binding affinity for its related ligands than for typical wildtype receptors [51].

Aflibercept has a significantly greater affinity for VEGFA compared with other monoclonal anti-VEGF antibodies [52]. Likewise, it has a higher affinity for the VEGF ligand even than the natural VEGF receptors, binding VEGF in a
$1: 1$ ratio $[51,52]$. In addition to binding to all VEGF-A isoforms, aflibercept also binds VEGF-B and to P1GF and, consequentially, efficiently blocks the binding and activation of VEGF via these receptors [51-53].

When aflibercept is administered intravitreally, the compound is rapidly distributed to the retina and slowly absorbed by the systemic circulation, with an average free drug maximum plasma concentration $\left(C_{\max }\right)$ of $0.02 \mu \mathrm{g} /$ $\mathrm{mL}$ (interval $0-0.054 \mu \mathrm{g} / \mathrm{mL}$ ) after a 2-mg intravitreal injection, in a period of 1-3 days, with concentrations becoming undetectable approximately 2 weeks after administration. It is important to note that the average $C_{\max }$ of aflibercept is approximately 50-500 times less than the amount needed to inhibit $50 \%$ of biologically active systemic VEGF in animal models [54]. In a study of healthy volunteers, after the intravitreal administration of $2 \mathrm{mg}$, the average $C_{\max }$ was 100 times less than the concentration of aflibercept necessary to bind systemic VEGF at half of maximum levels $(2.91 \mu \mathrm{g} / \mathrm{mL})$. Thus, it is extremely unlikely that systemic pharmacodynamic effects are produced, such as changes in blood pressure [53, 55].

\section{Management of Aflibercept in Clinical Practice}

After the results of the VIEW 1 and 2 trials [19] were published, and along with the aflibercept technical data sheet [52], it is advisable that the treatment of exudative AMD with this drug should be started with a loading dose of three consecutive monthly injections. It is likely that some patients could respond well with a bimonthly start, but there are no data to be able to confirm this and therefore this starting regimen is not recommended. Using this process and given that the injection is done in a programmed manner, medical visits and complementary tests such as OCT can be avoided. A focused patient history allows the detection of worsening signs and can rule out a massive bleed or a tear in the retinal pigmented epithelium (RPE). Once the loading dose is complete, the patient can be controlled with bimonthly injections.

In VIEW studies, more aflibercept- than ranibizumabtreated eyes were seen without retinal fluid at weeks 52 and $96[26,56]$. Recent subgroup analyses of the VIEW trials suggested a superior morphologic efficiency of aflibercept in reducing intraretinal and subretinal fluid as well as reducing RPE elevation, which suggest a superior anatomic efficacy of aflibercept compared with ranibizumab [26]. Although changes in central retina thickness were observed in the group with $2 \mathrm{mg}$ aflibercept every 8 weeks in the VIEW studies [19], which suggests that the anatomical suppression is not continuous with this bimonthly dosing, the VA results indicate that the large majority of patients can be treated effectively for 8 weeks because more than 
$90 \%$ of patients in this group did not lose vision. There is no evidence that these fluctuations in OCT negatively translate to VA [19]. Therefore, the technical data sheet shows that better results are not obtained when aflibercept is dosed every 4 weeks compared with every 8 weeks $(9.3$ vs. 8.4 ETDRS letters, in the VIEW studies) [26].

After 12 months, the treatment/follow-up intervals can be increased, as long as the neovascular membrane (NVM) does not show activity [56]. In eyes with clear NVM activity, such as RPE detachment or intraretinal fluid, bimonthly injections should be maintained or even monthly injections can be repeated [26].

After 12 months, a 'Treat and Extend' regimen can be started in cases of a "dry" retina (proactive treatment) in a similar manner to the pattern set out in the LUCAS study [57], lengthening the period 2 weeks each time, until a maximum interval of 3 months. There are no published data spanning a longer time interval; thus, currently the maximum recommended extension is 3 months. However, in the presence of an active NVM, it is advisable to treat and then shorten the follow-up interval by 2 weeks until again achieving a "dry" retina. In this way, an individual time period is established for each patient without neovascular activity and a fixed treatment regimen for each interval is established.

With regard to the question of when to stop treatment, the assessment of functional status of the other eye, patient availability, and patient agreement will be the basis for the retinal specialist to decide whether to or not to suspend intravitreal treatment.

\section{Approach to the Non-Responding Patient}

Variation in individual drug response is a common phenomenon. In anti-VEGF treated patients with exudative AMD, individual drug response is likely to be influenced by many factors that vary within the population. Despite a good initial response, some cases are refractory, with loss of vision and recurrent development of exudate, defined as the presence of fluid during at least 3 months after monthly treatment with bevacizumab or ranibizumab [58]. Two types of non-responders are contrasted: refractory patients and those that have a recurrence. The former present with persistent intraretinal or sub retinal liquid, despite treatment. The latter present with a good response, but then require repetitive doses to maintain the effect (prolonged monthly injections) [59]. Exploratory analyses of the data from the PIER trial stratified patients according to initial gain in VA and maintenance of initial gain after the loading dose of ranibizumab. Notably, $34 \%$ of patients do not improve their vision after three doses of ranibizumab (possible refractory patients) although most of them will maintain the initial vision. Only $40 \%$ of the patients maintained their initial gain in VA when injections were given less frequently than monthly. That suggests that many patients will need very frequent injections to control disease activity (recurrent patients) [60].

The mechanism responsible for this resistance is unknown, but various theories exist purporting that better anatomical and visual results can be obtained by switching to a different intravitreal medication [58, 59, 61]. The resistance could be due to the development of a tolerance or tachyphylaxis, which is manifested as a reduction in the response to successive treatments owing to an immune response. Likewise, chronic VEGF blockade would produce an alteration in the production of VEGF by macrophages from neovascular choroidal tissue. Because of this, some cases present with a better response after changing the anti-VEGF agent, having observed that up to $81 \%$ of patients favorably respond to the switching [62]. However, it is thought that perhaps the choroidal neovascularization becomes advanced again, which promotes the lack of response to conventional anti-VEGF therapy.

Owing to its mechanism of action with higher affinity than ranibizumab and bevacizumab to block the VEGF-A, VEGF-B, and P1GF domains, and its half-life, which is 18 days longer than that of ranibizumab [59], aflibercept could be more effective in advanced complex vascular cases [58]. Because of this, aflibercept could improve the effectiveness in patients with suboptimal responses with other anti-VEGF [59, 63].

The indications to change therapy to aflibercept are aimed to achieve a better anatomical result and to improve $\mathrm{VA}$, as well as to increase the interval between injections [59]. Various studies have analyzed the results of changing treatment in resistant patients, those refractory as well as recurrent, and have shown that these patients present with an anatomical improvement and VA stabilization [64, 65], permitting a small increase in the interval between injections [59]. Likewise, an important reduction in RPE detachments have been observed [65]. However, despite anatomical improvement, with respect to subretinal as well as intraretinal fluid [59], the VA does not significantly change in the majority of these cases, having been associated with subretinal scarring and photoreceptor loss [58]. Although these studies are interesting and suggest a benefit in converting to aflibercept, the absence of a well-balanced control group of non-switch patients and their retrospective nature make them difficult to interpret. It is possible the patients could have had similar anatomic improvements solely by changing to a fixed dosing with the previous drug [63]. There is only a recent, small, prospective comparative pilot study in 21 eyes who still needed monthly retreatment at the end of a 2-year clinical trial. These patients were randomized either to continue ranibizumab therapy or to 
convert to aflibercept therapy. Outcome measures included average interval between treatments, resolution of exudative signs, number of retreatments, and change in VA over 12 months (the third treatment year). Outcomes were similar in the two groups, with no statistical difference that suggests that in patients with exudative AMD requiring monthly retreatment with ranibizumab, there may be little clinical difference between changing to aflibercept and remaining on ranibizumab treatment [66].

To date, refractory or recurrent patients have been most often identified in cases treated with ranibizumab or bevacizumab because these drugs have been used the longest in clinical practice. To our knowledge, there are still no series of patients initially treated with aflibercept that do not respond, and switched then to ranibizumab or bevacizumab. There is a small series of cases of switching back treatment, which involves returning to bevacizumab treatment after switching to aflibercept. The reason for switching back to bevacizumab was cost for five cases, even though they were responsive to aflibercept. The other five cases were not responsive to aflibercept. Although the numbers of cases were small, data suggest that switching back from aflibercept to bevavizumab is not an effective strategy, as there was a deterioration in VA and macular thickness in the 10 patients who were switched back to bevacizumab [66]. In summary, it is necessary to perform randomized clinical trials to have a high grade of evidence regarding when and how the switching of medications should occur.

\section{Therapeutic Approach with Aflibercept in Polypoidal Choroidal Vasculopathy (PCV) and Retinal Angiomatous Proliferation (RAP)}

The PCV- and RAP-type lesions constitute subtypes of AMD with a few unique clinical characteristics. In general, the response to treatment with intravitreal injections of ranibizumab and bevacizumab is not usually as satisfactory. Although in both PCV and RAP aflibercept has demonstrated its efficacy both in naive patients and in refractory patients to other anti-angiogenic drugs, prospective clinical trials with a greater number of patients and a longer follow-up are needed to validate the promising preliminary results summarized below [67-74].

\subsection{PCV}

The optimal treatment option for PCV remains elusive, mainly because of a lack of high-quality randomized controlled trials. Most studies with current treatment strategies show good short-term visual outcome but poorer longerterm outcome. PCV treatment options include laser photocoagulation, photodynamic therapy (PDT), antiVEGF therapy, or a combination of these modalities. Current recommended guidelines support the combination of PDT with anti-VEGF therapy in the treatment of PCV $[75,76]$. PCV does not seem to respond as well to antiVEGF monotherapy probably because VEGF levels are elevated in eyes with PCV but not to the level seen with other subtypes of exudative AMD [77].

Ranibizumab monotherapy was studied as one of the treatment arms in the EVEREST and LAPTOP trials. The EVEREST study [78] was the first exploratory randomized controlled trial evaluating standard fluence PDT with or without ranibizumab $0.5 \mathrm{mg}$ and ranibizumab monotherapy in 61 Asian patients. At month six, the mean change in VA was 10.9 letters (verteporfin PDT + ranibizumab), 7.5 letters (verteporfin PDT), and 9.2 letters (ranibizumab). LAPTOP study was designed to assess the effect of PDT vs. anti-VEGF in terms of visual outcome. At 12 months, in the PDT arm $(n=47), 17.0 \%$ patients gained more than 0.2 logarithm of minimal angle of resolution (logMAR) units from baseline. In the ranibizumab arm $(n=46), 30.4 \%$ gained more than $0.2 \operatorname{logMAR}$, significantly better than the PDT arm. [79]. These two trials showed that although PDT may be more effective at polyp closure than ranibizumab, anti-VEGF therapy seemed to be better for improving or preventing visual loss in patients with PCV in the short term.

There are few studies assessing the role of bevacizumab in PCV, and most of them have a short follow-up duration or were not performed on treatment-naïve patients [75]. Cho and colleagues compared ranibizumab with bevacizumab monotherapy in a retrospective case control study and found no difference in polyp regression rate and VA at 6 months [80].

Kawashima and colleagues [69] compared the efficacy of aflibercept in 15 patients with AMD and 26 patients with PCV refractory to ranibizumab. After 6 months of aflibercept therapy, the patients with PCV improved one line of VA while there was no significant change in the patients with AMD. Additionally, patients with PCV had a significantly dryer retina without presence of fluid on OCT compared with patients with AMD (80.8 vs. $46.7 \%$, $p=0.024)$. No differences were observed between genotypes (ARMS2 and CFH) or response to treatment.

In another study, Ijiri and Sugiyama [70] evaluated the initial response to aflibercept in 33 patients with PCV without previous treatment. At 3 months, the average VA increased 8.9 ETDRS letters. Additionally, a dry macula via OCT in $97 \%$ of cases as well as a complete resolution of choroidal polyps via indocyanine green angiography in $48 \%$ of cases were observed. Saito and colleagues [73] have studied 43 cases of PCV refractory to ranibizumab and treated with aflibercept. All of the patients had 
followed a PRN treatment regimen for 12 months after a loading dose of three consecutive monthly injections of ranibizumab. Three months after switching treatment to aflibercept, the average VA significantly improved ( $p=0.0074)$ and the polyps disappeared in $50 \%$ of cases.

\subsection{RAP}

Anti-VEGF therapy for RAP has shown promising therapeutic efficacy, but studies to date have only reported short-term follow-up data. Parodi and colleagues performed a prospective, multicenter randomized clinical trial to compare the effects of bevacizumab and ranibizumab in the treatment of RAP over a 12-month follow-up. In the bevacizumab group, $20(77 \%)$ and $8(30 \%)$ eyes gained one or three lines of VA, respectively. In the ranibizumab group, $17(71 \%)$ and 7 (29\%) eyes showed an improvement of one or three lines, respectively [81]. Tsaousis and colleagues [74] published a series of 12 patients with RAPtype lesions without previous treatment that received threemonthly aflibercept injections. The VA improved in 10 patients $(83.3 \%)$ and the foveal thickness decreased in all cases. Future studies are warranted to ascertain the more appropriate practical therapeutic strategy for the management of RAP.

\section{Safety Data}

Safety data provided by the phase III trials, VIEW 1 and VIEW 2 [19, 55], indicate that, in general, aflibercept was well tolerated in all dose groups up to week 96, with an ocular and non-ocular adverse effect profile similar to ranibizumab [19]. The most frequent adverse effect (at least $5 \%$ of patients treated with aflibercept) was conjunctival hemorrhage (26.7 \%), eye pain (10.3\%), vitreous detachment $(8.4 \%)$, cataract $(7.9 \%)$, floating particles in the vitreous $(7.5 \%)$, and an increase in intraocular pressure (7.2\%). The serious adverse effects related to injections are rare, and include eye disorders, endophthalmitis, procedure complications, and increased in intraocular pressure.

The use of intravitreous VEGF inhibitors may expose patients to the theoretical risk of arterial thromboembolic events. In the VIEW 1 and 2 trials, the observed incidence of arterial thromboembolic events according to criteria set by the Antiplatelet Trialists' Collaboration [19] was $3.3 \%$ (60-1.824) in the treatment group with aflibercept (combining the patients that received different doses) and $3.2 \%$ (19-595) in patients treated with ranibizumab, during the 92 weeks of follow-up.

The data of a recent online meta-analysis, including 11 trials and a total of 8341 patients with AMD, showed that serious adverse effects and thrombotic events of all antiVEGF treatments were significantly more frequent compared with placebo, but the differences between treatments were difficult to evaluate [82].

\section{Treatment Algorithm with Aflibercept in Exudative AMD}

The results from the VIEW 1 and VIEW 2 trials [19, 55] allowed for the establishment of a treatment pattern with fixed doses of aflibercept that lead to less burden of care and good functional results [83]. This was achieved by starting a loading dose of three injections to be later followed by a fixed dose every 2 months during the first year. Because the doses will be administered independent of the anatomic and visual status of the patient, the complementary tests such as VA and OCT are not required in all visits [84]. Therefore, the fixed bimonthly patterns suppose a notable reduction in the healthcare burden not only by lowering the number of injections and visits, but also by reducing supplementary tests [83]. However, one must consider periodic testing with OCT not only in the affected eye but also especially in the contralateral eye to detect the appearance of disease and to administer an early treatment before VA loss. The technical data sheet of aflibercept approved in the EU allows switching to a personalized treatment in the second year, as can occur in the Treat and Extend protocol. In this way, the patients with a dry macula in OCT after the first year of bimonthly injections could lengthen the period between injections to 3 months. In this second year, the VA, OCT, and fundus examinations are obligatory in all visits because the appearance of classic sings of reactivation make it necessary to shorten the injection interval. This causes an increased demand of healthcare resources but helps to reduce over-treatment during the second year.

During the 2013 Annual Meeting of the American Society of Retinal Specialists, a subanalysis of the VIEW 1 and VIEW 2 studies was presented, showing that there is a subgroup of patients that benefit from retreatment with greater frequency during the first year (The Effect of Early, Persistent Fluid on Subsequent Visual Acuity in the VIEW 1 and VIEW 2 Studies of Neovascular AMD, Glenn Jaffe, Toronto, ASRS 2013 Annual Meeting). These patients have persistent fluid on OCT. In this subanalysis, patients that were followed with monthly aflibercept achieved better VA than patients treated with monthly ranibizumab or every 2 months with aflibercept. This would make it necessary to perform an examination after finalizing the loading dose. If the OCT shows absence of fluid, the patient can continue with the fixed 
pattern of bimonthly injections. This situation occurs in $80 \%$ of patients. If the OCT shows the presence of liquid (20\% of the remaining cases), the patient will obtain better visual results if maintained with monthly aflibercept injections until the macula is dry, followed then by a Treat and Extend protocol. This personalized treatment from the onset results in a higher demand of healthcare resources but has the potential advantage of improving visual results in $20 \%$ of patients. Additionally, like all personalized regimens, it is more difficult and complex to perform. Some studies also support the use of monthly aflibercept for treatment-resistant eyes [85-88]. If after a loading dose the OCT shows little improvement with respect to baseline, we can find ourselves dealing with a poor responder. In bimonthly visits, it is possible that the OCT shows some fluid but usually it is not associated with loss of VA with respect to the previous visit. The VIEW studies show that these slight increases in macular thickness are well tolerated during short periods without repercussions in VA, and thus a fixed bimonthly pattern will continue to be a good option despite the presence of a small quantity of intra or subretinal fluid on OCT.

\section{Conclusion}

Aflibercept can achieve beneficial effects in patients with exudative AMD similar to those obtained with monthly ranibizumab, using a bimonthly treatment regimen after the loading phase. To date, the safety profile of aflibercept is excellent and comparable to other anti-angiogenic treatments.

\section{Compliance with Ethical Standards}

Funding A. G. L., M. S. F., J. A., J. M. R. M., F. G. U., and L. A. B. received grants from the RETICs: RD07-0062: “Age- Related Ocular Diseases, Quality of Life, and Vision", and RETICS OFTARED (RD12/0034) "Prevention, Early Detection, and Treatment of the Prevalent Degenerative and Chronic Ocular Pathology" from the Instituto de Salud Carlos III from the Ministerio de Economia y Competitividad, Spain. This work has been partly funded by the PN I + D+i 2008-2011; thel ISCIII-Subdireccion General de Redes y Centros de Investigacion Cooperativa; and the European Program FEDER.

Conflict of interest A. G. L. has received fees for participation in advisory boards for Alcon, Allergan, Bayer, Thea, and Novartis. M. S. F. has received fees for participation in advisory boards for Alcon, Alimera, Allergan, Bayer, and Novartis. J. A. has received fees for participation in advisory boards for Alcon, Bayer and Novartis. J. M. R. M. has received fees for participation in advisory boards for Alcon, Allergan, Bayer, and Novartis. F. G. U. has received fees for participation in advisory boards for Alcon, Bayer, and Novartis. L. A. has received fees for participation in advisory boards for Alcon, Allergan, Bayer, and Novartis. N. R. reports no disclosures.
Open Access This article is distributed under the terms of the Creative Commons Attribution-NonCommercial 4.0 International License (http://creativecommons.org/licenses/by-nc/4.0/), which permits any noncommercial use, distribution, and reproduction in any medium, provided you give appropriate credit to the original author(s) and the source, provide a link to the Creative Commons license, and indicate if changes were made.

\section{References}

1. Bressler NM. Age-related macular degeneration is the leading cause of blindness. JAMA. 2004;291:1900-1.

2. Noble J, Chaudhary V. Age-related macular degeneration. CMAJ. 2010;182:1759.

3. Jonas JB. Global prevalence of age-related macular degeneration. Lancet Glob Health. 2014;2:e65-6.

4. Stewart MW. Pharmacokinetics, pharmacodynamics and preclinical characteristics of ophthalmic drugs that bind VEGF. Expert Rev Clin Pharmacol. 2014;7:167-80.

5. Penn JS, Madan A, Caldwell RB, Bartoli M, Caldwell RW, Hartnett ME. Vascular endothelial growth factor in eye disease. Prog Retin Eye Res. 2008;27:331-71.

6. García-Layana A, Thumann G, Groll J. Age macular degeneration: etiology, prevention, individualized therapies, cell therapy, and tissue engineering. J Ophthalmol. 2014;2014:287893. doi:10. 1155/2014/287893.

7. Zampros I, Praidou A, Brazitikos P, Ekonomidis P, Androudi S. Antivascular endothelial growth factor agents for neovascular age-related macular degeneration. J Ophthalmol. 2012;2012: 319728. doi:10.1155/2012/319728.

8. Semeraro F, Morescalchi F, Duse S, Parmeggiani F, Gambicorti E, Costagliola C. Aflibercept in wet AMD: specific role and optimal use. Drug Des Devel Ther. 2013;7:711-22.

9. Stewart MW. Aflibercept (VEGF Trap-Eye) for the treatment of exudative age-related macular degeneration. Expert Rev Clin Pharmacol. 2013;6:103-13.

10. Xu D, Kaiser D. Intravitreal aflibercept for neovascular age-related macular degeneration. Immunotherapy. 2013;5:121-30.

11. Miller JW, Le Couter J, Strauss EC, Ferrara N. Vascular endothelial growth factor $\mathrm{A}$ in intraocular vascular disease. Ophthalmology. 2013;120:106-14.

12. Sheibani N. Placental growth factor inhibition for choroidal neovascularization. J Ophthalmic Vis Res. 2013;8:1-3.

13. Klein R, Klein BE, Tomany SC, Moss SE. Ten-year incidence of age related maculopathy and smoking and drinking: the Beaver Dam Eye Study. Am J Epidemiol. 2002;156:589-98.

14. Sainz-Gómez C, Fernández-Robredo P, Salinas-Alamán A, Montañés JM, Escudero-Berasategui JM, et al. Prevalence and causes of bilateral blindness and visual impairment among institutionalized elderly people in Pamplona, Spain. Eur J Ophthalmol. 2010;20:442-50.

15. Ambati J, Ambati BK, Yoo SH, Ianchulev S, Adamis AP. Agerelated macular degeneration: etiology, pathogenesis, and therapeutic strategies. Surv Ophthalmol. 2003;48:257-93.

16. Rosenfeld PJ, Brown DM, Heier JS, Boyer DS, Kaiser PK, Chung $\mathrm{CY}$, et al. Ranibizumab for neovascular age-related macular degeneration. N Engl J Med. 2006;355:1419-31.

17. Kaiser PK, Brown DM, Zhang K, Hudson HL, Holz FG, Shapiro $\mathrm{H}$, et al. Ranibizumab for predominantly classic neovascular agerelated macular degeneration: subgroup analysis of first-year ANCHOR results. Am J Ophthalmol. 2007;144:850-7.

18. Comparison of Age-related Macular Degeneration treatments Trials (CATT) Research Group, Martin DF, Maguire MG, Fine SL, Ying GS, Jaffe GJ, Grunwald JE, et al. Ranibizumab and 
bevacizumab for treatment of neovascular age-related macular degeneration: two-year results. Ophthalmology 2012;119: 1388-98.

19. Heier JS, Brown DM, Chong V, Korobelnik JF, Kaiser PK, Nguyen QD, et al. Intravitreal aflibercept (VEGF trap-eye) in wet age-related macular degeneration. Ophthalmology. 2012;119: 2537-48.

20. Brown DM, Michels M, Kaiser PK, Heier JS, Sy JP, Ianchulev T. Ranibizumab versus verteporfin photodynamic therapy for neovascular age-related macular degeneration: two-year results of the ANCHOR study. Ophthalmology. 2009;116:57-65.

21. Holz FG, Amoaku W, Donate J, Guymer RH, Kellner U, Schlingemann RO, et al. Safety and efficacy of a flexible dosing regimen of ranibizumab in neovascular age-related macular degeneration: the SUSTAIN study. Ophthalmology. 2011;118: 663-71.

22. Lalwani GA, Rosenfeld PJ, Fung AE, Dubovy SR, Michels S, Feuer W, et al. A variable-dosing regimen with intravitreal ranibizumab for neovascular age-related macular degeneration: year 2 of the PrONTO Study. Am J Ophthalmol. 2009;148:43-58.

23. Chakravarthy U, Harding SP, Rogers CA, Downes SM, Lotery AJ, Culliford LA, et al. Alternative treatments to inhibit VEGF in age-related choroidal neovascularisation: 2-year findings of the IVAN randomised controlled trial. Lancet. 2013;382:1258-67.

24. CATT Research Group, Martin DF, Maguire MG, Ying GS, Grunwald JE, Fine SL, Jaffe GJ. Ranibizumab and bevacizumab for neovascular age-related macular degeneration. N Engl J Med 2011;364:1897-908.

25. Lad EM, Hammill BG, Qualls LG, Wang F, Cousins SW, Curtis LH. Anti-VEGF treatment patterns for neovascular age-related macular degeneration among Medicare beneficiaries. Am J Ophthalmol. 2014;158:537-43.

26. Schmidt-Erfurth U, Chong V, Loewenstein A, Larsen M, Souied E, Schlingemann R, et al. Guidelines for the management of neovascular age-related macular degeneration by the European Society of Retina Specialists (EURETINA). Br J Ophthalmol. 2014;98:1144-67.

27. Engelbert M, Zweifel SA, Freund KB. "Treat and extend" dosing of intravitreal antivascular endothelial growth factor therapy for type 3 neovascularization/retinal angiomatous proliferation. Retina. 2009;29:1424-31.

28. Engelbert M, Zweifel SA, Freund KB. Long term follow up for type 1 (subretinal pigment epithelium) neovascularization using a modified "Treat and Extend" dosing regimen of antivascular endothelial growth factor therapy. Retina. 2010;30:1368-75.

29. Gupta OP, Shienbaum G, Patel AH, Fecarotta C, Kaiser RS, Regillo CD. A treat and extend regimen using ranibizumab for neovascular age-related macular degeneration clinical and economic impact. Ophthalmology. 2010;117:2134-40.

30. Oubraham H, Cohen SY, Samimi S, Marotte D, Bouzaher I, Bonicel $\mathrm{P}$, et al. Inject and extend dosing versus dosing as needed: a comparative retrospective study of ranibizumab in exudative age-related macular degeneration. Retina. 2011;31: 26-30.

31. Toalster N, Russell M, Ng P. A 12-month prospective trial of inject and extend regimen for ranibizumab treatment of age-related macular degeneration. Retina. 2013;33:1351-8.

32. Mitchell P, Korobelnik JF, Lanzetta P, Holz FG, Prünte C, Schmidt-Erfurth U, et al. Ranibizumab (Lucentis) in neovascular age-related macular degeneration: evidence from clinical trials. Br J Ophthalmol. 2010;94:2-13.

33. Freund KB, Mrejen S, Gallego-Pinazo R. An update on the pharmacotherapy of neovascular age-related macular degeneration. Expert Opin Pharmacother. 2013;14:1017-28.

34. Arias L, Roman I, Masuet-Aumatell C, Rubio MJ, Caminal JM, Catala J, Pujol O. One-year results of a flexible regimen with ranibizumab therapy in macular degeneration relationship with the number of injections. Retina. 2011;31:1261-7.

35. Lala C, Framme C, Wolf-Schnurrbusch UEK, Wolf S. Three year results of visual outcome with disease activity-guided ranibizumab algorithm for the treatment of exudative age-related macular degeneration. Acta Ophthalmol. 2013;91:526-30.

36. Monés J, Biarnes M, Trindade F, Casaroli-Marano R. FUSION: ranibizumab in treatment-naïve patients with exudative age-related macular degeneration and relatively good baseline visual acuity. Graefes Arch Clin Exp Ophthalmol. 2012;250:1737-44.

37. Mantel I, Niderprim SA, Gianniou C, Deli A, Ambresin A. Reducing the clinical burden of ranibizumab treatment for neovascular age-related macular degeneration using an individual planned regimen. Br J Ophthalmol. 2014;98:1192-6.

38. Gianniou C, Dirani A, Ferrini W, Marchionno L, Decugis D, Deli A, Ambresin A, Mantel I. Two-year outcome of an observe-andplan regimen for neovascular age-related macular degeneration: how to alleviate the clinical burden with maintained functional results. Eye. 2014;29(3):450-1.

39. Cohen SY, Mimoun G, Oubraham H, Zourdani A, Malbrel CH, et al. Changes in visual acuity in patients with wet age-related macular degeneration treated with intravitreal ranibizumab in daily clinical practice: the Lumiere Study. Retina. 2013;33: 474-81.

40. Holz FG, Bandello F, Gillies M, Mitchell P, Osborne A, Sheidow $\mathrm{T}$, et al. Safety of ranibizumab in routine clinical practice: 1-year retrospective pooled analysis of four European neovascular AMD registries within the LUMINOUS programme. Br J Ophthalmol. 2013;97:1161-7.

41. Holz FG, Tadayoni R, Beatty S, Berger A, Cereda MG, Cortez R, et al. Multi-country real-life experience of anti-vascular endothelial growth factor therapy for wet age-related macular degeneration. Br J Ophthalmol. 2015;99:220-6.

42. Pagliarini S, Beatty S, Lipkova B, Perez-Salvador E, Reynders S, Gekkieva M, et al. Observational study of ranibizumab $0.5 \mathrm{mg}$ in patients with neovascular age-related macular degeneration in routine clinical practice: the EPICOHORT Study. J Ophthalmol 2014;2014:857148.

43. Writing Committee for the UK Age-Related Macular Degeneration EMR Users Group. The neovascular age-related macular degeneration database: multicentre study. Report 1. Ophthalmology. 2014;121:1092-101.

44. Marquesa IP, Fonseca P, Cachuloa ML, Piresa I, Figueira J, Faria de Abreub JR, et al. Treatment of exudative age-related macular degeneration with intravitreal ranibizumab in clinical practice: a 3-year follow-up. Ophthalmologica. 2013;229:158-67.

45. Gabai A, Daniele Veritti D, Lanzetta P. One-year outcome of ranibizumab for neovascular age-related macular degeneration: a thorough analysis in a real-world clinical setting. Eur J Ophthalmol. 2014;24:396-401.

46. Rasmussen A, Bloch SB, Fuchs J, Hansen LH, Larsen M, Lacour $\mathrm{M}$, et al. A 4-year longitudinal study of 555 patients treated with ranibizumab for neovascular age-related macular degeneration. Ophthalmology. 2013;120:2630-6.

47. Zhu M, Chew JK, Broadhead GK, Luo Y, Joachim N, Hong T, Syed A, et al. Intravitreal ranibizumab for neovascular age-related macular degeneration in clinical practice: five-year treatment outcomes. Graefes Arch Clin Exp Ophthalmol. 2015;253: 1217-25.

48. Wolf A, Kampik A. Efficacy of treatment with ranibizumab in patients with wet age-related macular degeneration in routine clinical care: data from the COMPASS health services research. Graefes Arch Clin Exp Ophthalmol. 2014;252:647-55.

49. Fernández-Robredo P, Sancho A, Johnen S, Recalde S, Gama N, Thumann G, Groll J, García-Layana A. Current treatment limitations in age-related macular degeneration and future approaches 
based on cell therapy and tissue engineering. J Ophthalmol. 2014;2014:510285. doi:10.1155/2014/510285.

50. Casaroli-Marano R, Gallego-Pinazo R, Fernández-Blanco CT, Figueroa MS, Pina Marín B, Fernández-Baca Vaca G, et al. Agerelated macular degeneration: clinical findings following treatment with antiangiogenic drugs. J Ophthalmol. 2014;2014: 346-60. doi:10.1155/2014/346360.

51. Frampton JE. Aflibercept for intravitreal injection: in neovascular age-related macular degeneration. Drugs Aging. 2012;29:839-46.

52. Yang J, Wang X, Fuh G, Yu L, Wakshull E, Khosraviani M, Day ES, Demeule B, Liu J, Shire SJ, Ferrara N, Yadav S. Comparison of binding characteristics and in vitro activities of three inhibitors of vascular endothelial growth factor A. Mol Pharm. 2014;11: 3421-30.

53. Stewart MW, Rosenfeld PJ. Predicted biological activity of intravitreal VEGF trap. Br J Ophthalmol. 2008;92:667-8.

54. Sophie R, Akhtar A, Sepah YJ, Ibrahim M, Bittencourt M, Do DV, et al. Aflibercept: a potent vascular endothelial growth factor antagonist for neovascular age-related macular degeneration and other retinal vascular diseases. Biol Ther. 2012;2:3.

55. Thai HT, Veyrat-Follet C, Vivier N, Dubruc C, Sanderink G, Mentré $\mathrm{F}$, et al. A mechanism-based model for the population pharmacokinetics of free and bound aflibercept in healthy subjects. Br J Clin Pharmacol. 2011;72:402-14.

56. Schmidt-Erfurth U, Kaiser PK, Korobelnik JF, Brown DM, Chong V, Nguyen QD, et al. Intravitreal aflibercept injection for neovascular age-related macular degeneration: ninety-six-week results of the VIEW studies. Ophthalmology. 2014;121:193-201.

57. Berg K, Pedersen TR, Sandvik L, Bragadóttir R. Comparison of ranibizumab and bevacizumab for neovascular age-related macular degeneration according to LUCAS treat-and-extend protocol. Ophthalmology. 2015;122:146-52.

58. Bakall B, Folk JC, Boldt HC, Sohn EH, Stone EM, Russell SR, et al. Aflibercept therapy for exudative age-related macular degeneration resistant to bevacizumab and ranibizumab. Am $\mathbf{J}$ Ophthalmol. 2013;156(15-22):e1.

59. Yonekawa Y, Andreoli C, Miller JB, Loewenstein JI, Sobrin L, Eliott D, et al. Conversion to aflibercept for chronic refractory or recurrent neovascular age-related macular degeneration. Am J Ophthalmol. 2013;156(29-35):e2.

60. Holz FG, Korobelnik JF, Lanzetta P, Mitchell P, Schmidt-Erfurth $\mathrm{U}$, Wolf $\mathrm{S}$, et al. The effects of a flexible visual acuity-driven ranibizumab treatment regimen in age-related macular degeneration: outcomes of a drug and disease model. Invest Ophthalmol Vis Sci. 2010;51:405-12.

61. Ho VY, Yeh S, Olsen TW, Bergstrom CS, Yan J, Cribbs BE, et al. Short-term outcomes of aflibercept for neovascular agerelated macular degeneration in eyes previously treated with other vascular endothelial growth factor inhibitors. Am J Ophthalmol. 2013;156(23-8):e2.

62. Gasperini JL, Fawzi AA, Khondkaryan A, Lam L, Chong LP, Eliott D, et al. Bevacizumab and ranibizumab tachyphylaxis in the treatment of choroidal neovascularisation. Br J Ophthalmol. 2012;96:14-20.

63. Singh RP, Srivastava S, Ehlers JP, Bedi R, Schachat AP, Kaiser PK. A single-arm, investigator-initiated study of the efficacy, safety and tolerability of intravitreal aflibercept injection in subjects with exudative age-related macular degeneration, previously treated with ranibizumab or bevacizumab: 6-month interim analysis. Br J Ophthalmol. 2014;98(Suppl 1):i22-7.

64. Schachat AP. Switching anti-vascular endothelial growth factor therapy for neovascular age-related macular degeneration. Am J Ophthalmol. 2013;156(1-2):e1.

65. Fassnacht-Riederle H, Becker M, Graf N, Michels S. Effect of aflibercept in insufficient responders to prior anti-VEGF therapy in neovascular AMD. Graefes Arch Clin Exp Ophthalmol. 2014;252:1705-9.

66. Mantel I, Gianniou C, Dirani A. Conversion to aflibercept therapy versus continuing with ranibizumab therapy for neovascular agerelated macular degeneration dependent on monthly ranibizumab treatment. Retina. 2015. doi:10.1097/IAE.0000000000000664.

67. da Moon RC, Lee DK, Kim SH, You YS, Kwon OW. Aflibercept treatment for neovascular age-related macular degeneration and polypoidal choroidal vasculopathy refractory to anti-vascular endothelial growth factor. Korean J Ophthalmol. 2015;29: 226-32.

68. Yonekawa Y. Aflibercept for the treatment of refractory polypoidal choroidal vasculopathy. Can J Ophthalmol. 2013;48: e59-60.

69. Kawashima Y, Oishi A, Tsujikawa A, Yamashiro K, Miyake M, Ueda-Arakawa N, et al. Effects of aflibercept for ranibizumabresistant neovascular age-related macular degeneration and polypoidal choroidal vasculopathy. Graefes Arch Clin Exp Ophthalmol. 2014. doi:10.1007/s00417-014-2838-5.

70. Ijiri S, Sugiyama K. Short-term efficacy of intravitreal aflibercept for patients with treatment-naïve polypoidal choroidal vasculopathy. Graefes Arch Clin Exp Ophthalmol. 2015;253:351-7.

71. Inoue M, Arakawa A, Yamane S, Kadonosono K. Short-term efficacy of intravitreal aflibercept in treatment-naïve patients with polypoidal choroidal vasculopathy. Retina. 2014;34:2178-84.

72. Miura M, Iwasaki T, Goto H. Intravitreal aflibercept for polypoidal choroidal vasculopathy after developing ranibizumab tachyphylaxis. Clin Ophthalmol. 2013;7:1591-5.

73. Saito M, Kano M, Itagaki K, Oguchi Y, Sekiryu T. Switching to intravitreal aflibercept injection for polypoidal choroidal vasculopathy refractory to ranibizumab. Retina. 2014;34:2192-201.

74. Tsaousis KT, Konidaris VE, Banerjee S, Empeslidis T. Intravitreal aflibercept treatment of retinal angiomatous proliferation: a pilot study and short-term efficacy. Graefes Arch Clin Exp Ophthalmol. 2015;253:663-5.

75. Wong CW, Wong TY, Cheung CM. Polypoidal choroidal vasculopathy in Asians. J Clin Med. 2015;4:782-821.

76. Davis SJ, Lauer AK, Flaxel CJ. Polypoidal choroidal vasculopathy in white patients. Retina. 2014;34:2185-91.

77. Tong JP, Chan WM, Liu DT, et al. Aqueous humor levels of vascular endothelial growth factor and pigment epitheliumderived factor in polypoidal choroidal vasculopathy and choroidal neovascularization. Am J Ophthalmol. 2006;141:456-62.

78. Koh A, Lee WK, Chen LJ, Chen SJ, Hashad Y, Kim H, et al. EVEREST study: efficacy and safety of verteporfin photodynamic therapy in combination with ranibizumab or alone versus ranibizumab monotherapy in patients with symptomatic macular polypoidal choroidal vasculopathy. Retina. 2012;32: 1453-64.

79. Oishi A, Kojima H, Mandai M, Honda S, Matsuoka T, Oh H, et el. Comparison of the effect of ranibizumab and verteporfin for polypoidal choroidal vasculopathy: 12-month LAPTOP study results. Am J Ophthalmol 2013; 156:644-51.

80. Cho HJ, Baek JS, Lee DW, Kim CG, Kim JW. Short-term effectiveness of intravitreal bevacizumab vs. ranibizumab injections for patients with polypoidal choroidal vasculopathy. Korean J Ophthalmol. 2012;26:157-62.

81. Parodi MB, Iacono P, Menchini F, Sheth S, Polini G, et al. Intravitreal bevacizumab versus ranibizumab for the treatment of retinal angiomatous proliferation. Acta Ophthalmol. 2013;91: 267-73.

82. Schmid MK, Bachmann LM, Fäs L, Kessels AG, Job OM, Thiel MA. Efficacy and adverse events of aflibercept, ranibizumab and bevacizumab in age-related macular degeneration: a trade-off analysis. Br J Ophthalmol. 2015;99:141-6. 
83. García-Layana A, Arias L, Figueroa MS, Araiz J, Ruiz-Moreno JM, García-Arum J, et al. A Delphi study to detect deficiencies and propose actions in real life treatment of neovascular agerelated macular degeneration. J Ophthalmol. 2014;2014:595132. doi:10.1155/2014/595132.

84. Elshout M, van der Reis MI, Webers CA, Schouten JS. The costutility of aflibercept for the treatment of age-related macular degeneration compared to bevacizumab and ranibizumab and the influence of model parameters. Graefes Arch Clin Exp Ophthalmol. 2014;252:1911-20.

85. Cho H, Shah CP, Weber M, Heier JS. Aflibercept for exudative AMD with persistent fluid on ranibizumab and/or bevacizumab. Br J Ophthalmol. 2013;97:1032-5.
86. Arcinue CA, Ma F, Barteselli G, Sharpsten L, Gomez ML, Freeman WR. One-year outcomes of aflibercept in recurrent or persistent neovascular age-related macular degeneration. Am J Ophthalmol. 2015;159:426-36.

87. Khanani AM. Clinical experience with fixed bimonthly aflibercept dosing in treatment-experienced patients with neovascular age-related macular degeneration. Clin Ophthalmol. 2015;22(9): 1315-20.

88. McKibbin M, Devonport H, Gale R, Gavin M, Lotery A, et al. Aflibercept in wet AMD beyond the first year of treatment: recommendations by an expert roundtable panel. Eye. 2015;29(Suppl 1):S1-11 